\title{
Logarithmic Level Comparison for Small Deviation Probabilities
}

\author{
Fuchang Gao $\cdot$ Wenbo V. Li
}

Published online: 3 August 2007

(C) Springer Science+Business Media, LLC 2007

Erratum to: J Theor Probab, Vol. 20, No. 1, March 2007 DOI: 10.1007/s10959-006-0027-0

This article was inadvertently published twice. The publisher regrets the error.

Please refer to the original version of this article that appears in the Journal of Theoretical Probability, Vol. 19, No. 3, July 2006. The DOI of the original article is 10.1007/s10959-006-0026-1.

The online version of the original article can be found at: http://dx.doi.org/10.1007/s10959-006-0027-0

F. Gao

Department of Mathematics, University of Idaho, Moscow, ID 83844-1103, USA

e-mail: fuchang@uidaho.edu

W.V. Li ( $\varangle)$

Department of Mathematical Sciences, University of Delaware, Delaware, USA

e-mail:wli@math.udel.edu 